\title{
The Development of Nuclear Codes in Japan, (I)
}

\author{
By Tasaburo YAMADA* and Toshio AOKI**
}

The application of the digital computer in nuclear engineering has been increasing rapidly, and many scientists and engineers are engaged in this field. In order to coordinate their activities, the Japan Nuclear Codes Group (JNCG) and the Shielding Codes Group (SCG) were organized in the middle of 1959. The following paper describing the historical and present status was prepared by these groups and presented at Seminar on Codes for Reactor Computation at Vienna, Austria (April 25 29, 1960), sponcered by International Atomic Energy Agency (IAEA).

For the editorial convenience, the Lists of the Registered Codes will be presented in the next number of this Journal

The editoiral staffs of this compilation were:
K. Arai
(HITACHI)
K. Ono
(CRIEPI)
Y. Arai
(JAPCO)
M. Takada
(TOKYO UNIV.)
M. Hachiya
(MITSUI)
T. Takeshita
(IBMJ)
T. Kawai (HITACHII)
S. Terasawa
(HITACHI)
T. Morita
(ETL)
M. Tokizawa
(NAIG)
T. Nakayama
(JAERI)
A. Tsuruo
(KAJIMA)

\section{Introductory Period of COMPUTER APPLLICATION TO NuClear ENGINEERING}

The peaceful uses of atomic energy in Japan were started in 1954, when the related committees were organized in the Government. After the first Geneva Conference, this trend became more remarkable.

At that time, the automatic digital computer, which is now considered a very important tool for the research of nuclear energy, was not ready for practical uses.

Although scientists and engineers were devoting great efforts for developing computers, only small pilot models were completed.

Furthermore, until that time foreign mediumscale computers had not been imported. Under these circumstances, only a few people understood the significance of the digital computer in the field of nuclear engineering.

The first application of digital computer was made in 1955, "15-Group Critical Calulation of a Reflected Water Boiler Reactor" (HITACHI) ** using IBM-602A. In 1956 the ETL-Mark II, the first domestic relay type computer for scientific purposes in Japan, was used in "10-Group Critical Calculation of Fast Reactor" (ETL). After a while, a computing center of FACOM-128, which is a modified and commercial model of ETL-Mark II, was opened, and made much contribution to the reactor calculation.

A small punched card machine (CPC) was also used for the "Critical Calculation of Homogeneous Heavy Water Reactor" (TOSHIBA). Realizing the limitation of small scale machines and analytical approaches, people began to recognize the necessity of

* 山田太三郎 Chairman JNCG : Electro-Technical Lab. (電気試䝠所)

**青木敏男 Chairman SCG:Japan Atomic Energy Res. Inst. (日.本原子力研究所)

** $c f$. List of abbreviation of establishments (p. 347) 
numerical treatment of the problems by large and high speed computers.

Thus, the installation of high speed computers and the training of the programming engineers gained ground and much attention were paid to them. However, our scientists were continuing to carry out many works with considerable success by relay computers, in spite of their being small and slow. An IBM-602A was also used in design works of JRR-3 (Japan Research Reactor No.3-Japan-made Reactor No.1)

On the other hand, the computer project made much progress. The machines completed in this period were ETL-Mark IV (the first transistor type computer) at Electrotechnical Lakoratory, PC-1 at Tokyo University and HIPAC-I at Hitachi Ltd. (the machines with parametron computing components which were developed in Japan a few years ago). Being stimulated by these achievements, several manufacturing companies entered into the production stage of digital computers. Its results appeared in 1958 as the completion of several domestic medium scale computers. A number of data processing systems for business uses were also imported.

At that time, Japan was considering the import of a British-type power reactor. In order to estimate the economical feasibility of that reactor, the relay-type automatic computer (ETL-Mark II) ${ }^{*}$ was used for burnup calculation, the result of which was presented in the 2nd Geneva Conference (P/1339). "Four-Group Two Dimensional Critical Calculation of Water Moderated Reactor of Cylindrical Geometry' (NAIG) was also performed by the same computer. This is the predominant research in the critical calculation in this period and attracted much attention of reactor physicists.

Following these studies, the "MERCURY-0 Code" (HITACHI ; FACOM-128) for the parametric study of the reactor core and
"SPECTRUM-Series Codes" (HITACHI; FACOM-128) were developed, and they were much used for the reactor design study, especially, for the analysis of positive temperature coefficient on the British-type reactor. "BWR Preliminary Calculation" (NAIG; UNIVAC-120) was made by a small punched card machine in the early of 1958.

\section{Development Period}

In the middle of 1958 ,' we entered into the second stage of computer applications to the nuclear field. IBM-650s were installed at JAERI and MAPI, a Bendix-G15D at MELCO and a USSC at TOSHIBÁ. The IBM computing center was also opened with an IBM-650 and its full auxiliary equipments.

Some domestic computers were also made available for practical uses. The typical computers used for reactor calculation, are ETL-Mark IV (transistor) at Electrotechnical Laboratory, HIPAC-101 (parametron) at HITACHI, Ltd. and JEIDACs at JEIDA. The computing center (JEIDA) of the domestic machines was opened with the help of the Japanese Government, where the training projects of programmers were started.

In March 1959, the Meteorological Agency of the Japanese Government installed an IBM-704 (8K-8K) for weather forecast. It is the only large scale computer in Japan.

The relay computers, which made much contribution in the early period, are still playing a supplementary role. With the increase of availability of computers, the branches to which computers are applied, have correspondingly increased - the problems of group diffusion, burn-up, Xe-oscillation, reactor kinetics, physics, Monte Carlo, transport theory, fusion, reactor safety, shielding and so on. The number of scientists associated with computers has also been increasing rapidly.

In the course of nuclear code develop-

* The first word in parentheses is the name of the organization and the second is that of the computer. 
ment, emphasis has been placed on the problems of group diffusion, burn-up and boiling water reactors. At JAERI, the extensive applications of computers have been considered in connection with the problem of a semi-homogeneous reactor project.

A few typical codes of each category will be described in the following sections:

\section{Group diffusion}

"Two-Group Two Region Code" (JAERI; IBM-650) is the first registered code in the IBM Library. It deals with the analytical solution of spherical reactors, and is used for preliminary survey calculation. "SUNRISE-2B" (HITACHI; HIPAC-1) is a two-dimension, two-group, critical calculation code, for boiling water reactors. In this code, backward method and PeacemanRachford acceleration method were first employed in Japan; their usefullness greatly impressed our nuclear physicists. Several codes of the similar kind have been developed at various organizations. "CUBE" (NAIG. IBM-650) is a code for three-dimensional critical calculation by synthesizing the onedimensional analytical solution. This code is applied for the survey study of a small-size reactor. "ZEUS-1" (HITACHI; IBM-650) is a code which deals with two-dimension, few-group, multi-region diffusion equation for BWR, for which a medium scale computer is utilized to the limit of its capability.

\section{Burn-up}

In 1958, the extensive research was made for the purpose of studying the economical feasibility of power reactors and of planning a long-term power reactor development schedule. "Fuel Cycle" (CRIEPI; FACOM-128) was designed to clarify the possibility of plutonium recycling. The signifcance of digital computers in reactor physics was again proved by this calculation. "MARS Series" (HITACHI; IBM-650) is a onedimension, burn-up code for BWR. It has been extensively applied for the burn-up problems. One of its characteristics is the flexibility to handle intricate radial shuffling.

\section{Kinetics}

"VULCAN Series" (HITACHI;IBM-650) is for IBM-650 and deals with the transient phenomena of a water moderated reactor, especially with temperature distribution in fuel rods, heat flux through fuel surfaces and delayed neutron density during power transient. This is considered to be useful for the kinetics and safety analysis of power reactors. "Dynamic and Safety Calculation of BritishType Reactor"'(JAPCO;FACOM-128, NEAC .2203) was designed to solve the problem associated with the operation of the reactor, such as start-up, accidents, Xe spatial oscillation and so on

"DIANA" (HITACHI; HIPAC-101) deals with the transient hydrodynamic equation of two phase flow and void reactivity response in BWR. Elaborate efforts were made for the treatment of transient behavior and the solution of hyperbolic-type partial differential equations.

\section{Physics}

"Calculation of Thermal Neutron Spectrum"(MAPI; IBM-650) gives the thermal group constants by calculating the WignerWilkins spectrum. Several similar works are now being planned by various organizations "SONNE"' (NAIG;USSC) calculates the inelastic scattering cross section and the directional distribution of elastically scattered neutron by using the optical model. This code has come out as a result of deep interest of our scientists in this theme.

Two codes have been developed for BWR design, which include the calculation of void dependent nuclear constants. One of them, "MERCURY Series"(HITACHI; IBM-650), is a code for criticality calculation, and the other, "HERMES Series" (HITACHI; IBM-650) obtains three-group constants. They 
supply nuclear constants for the following calculations.

The codes related to experimental results have not been developed yet, because of the delay of reactor experiment projects.

\section{Transport}

"Sn Code"(JAERI; IBM-650) has been developed for IBM-650. It is noted that a medium scale machine is used for $S_{n}$ solution.

\section{Monte Carlo}

Some of our scientists are interested in Monte Carlo method. "PACIFIC Series" (KAJIMA, ISM; FACOM-128) is the first Monte Carlo code programmed in Japan and treats the scattering of gamma-ray in various shaped media by the collision density method. More refined approaches are in progress for the leakage calculation in complicated geometry. "FUSION-1" (HITACHI; HIPAC-101) gives the history of ions trapped in a mirror type magnetic bottle. It is an application of ion cyclotron resonance for fusion projects.

Applications of Monte Carlo method to various branches of nuclear physics are being considered.

\section{Shielding}

The major works in this category are "Shadow Shield Calculation at Reactor Accident"'(TEPCO;NEAC-2203) and "Calculation of Radioactivity in Coolant" (MAPI; BendixG15D). The Shielding Codes Group (SCG) has many projects in this branch.

Summarizing the above, the development after the middle of 1959 is outstanding. Remarkable is the fact that great efforts have been made to solve large problems by smalland medium-scale computers. As an inevitable result, many of the above-mentioned codes have less generality.

As a whole, the limitation of medium scale computers has been widely recognized among the nuclear scientists. To meet this situation, several organizations are considering the installation of large scale digital computers. Many a scientist has started programming for the IBM-704. Among these projects is "Burn-up Calculation Code for BWR" (ETL;IBM-704) by two-dimension treatment, which is approaching completion.

\section{ORgANIZATIONS OF RESEARCHERS .}

Due to the rapid advancement of nuclear code works and the increase of the programming engineers in 1959, the following groups have been organized to coordinate their activities:

The Japan Nuclear Codes Group (JNCG) The Shielding Codes Group (SCG)

The purpose of the JNCG includes the discussion of new ideas, the exchange of information, the registration of new codes and the study of foreign codes. The group consists of the some fifty scientists and engineers who represent nearly twenty organizations. About sixty computer programs have been so far registered, the list of which will be presented in Part (II).

The group covers almost all programming engineers in nuclear field and is playing an important role in Japan. In the years to come, we attempt to ensure the availability of large scale computers and to develop nuclear codes for them.

Thirty scientists belong to the SCG. Japanese people are much concerned about the radiation hazard due to their historical background. To build nuclear facilities, the precise estimation of radiation and safety is greatly required. We also should solve the problem of minimizing the weight of shielding material for nuclear propulsion ships.

This group is making joint efforts for the development and use of the general codes for these problems. The whole projects of the group are shown in Appendix C. 


\section{List of abbreviation of establishments}

\begin{tabular}{|c|c|c|c|}
\hline CRIEPI & $\begin{array}{l}\text { Central Research Institute of Electric } \\
\text { Power Industry }\end{array}$ & $\begin{array}{l}\text { IBMJ } \\
\text { KAJIMA }\end{array}$ & $\begin{array}{l}\text { IBM Japan, Ltd. } \\
\text { Kajima Construction Co., L.td. }\end{array}$ \\
\hline ECL & Electrical Communication Laboratory & MAPI & Mitsubishi Atomic Power Industries \\
\hline ETL & Electrotechnical Laboratory & & Inc. \\
\hline FUJI & Fuji Electric Manufacturing Co, Ltd. & MELCO & Mitsubishi Electric Manufacturing \\
\hline FUJICM & Fuji Communication Apparatus & & Co., Ltd. \\
\hline HITACHI & $\begin{array}{l}\text { Manufacturing Co., Ltd. } \\
\text { Hitachi, Ltd. }\end{array}$ & MITSUI & $\begin{array}{l}\text { Mitsui Shipbuilding and Engineer- } \\
\text { ing Co., Ltd. }\end{array}$ \\
\hline $\begin{array}{l}\text { HOKUSHIN } \\
\text { ISM }\end{array}$ & $\begin{array}{l}\text { Hokushin Electric Works, Ltd. } \\
\text { Institute of Statistical Mathematics }\end{array}$ & NAIG & $\begin{array}{l}\text { Nippon Atomic Industry Group Co., } \\
\text { Ltd. }\end{array}$ \\
\hline JAERI & $\begin{array}{l}\text { Japan Atomic Energy Research } \\
\text { Institute }\end{array}$ & $\begin{array}{l}\text { NEC } \\
\text { OKI }\end{array}$ & $\begin{array}{l}\text { Nippon Electric Co., Ltd. } \\
\text { Oki Electric Industry Co., Ltd. }\end{array}$ \\
\hline JAPCO & Japan Atomic Power Co., Ltd. & TEPCO & Tokyo Electric Power Co., Ltd. \\
\hline JEIDA & $\begin{array}{l}\text { Japan Electronic Industry Develop- } \\
\text { ment Association }\end{array}$ & TOSHIBA & Tokyo Shibaura Electric Co., Ltd. \\
\hline
\end{tabular}

\section{[Appendix A] History of Nuclear Code Developments in Japan}

1952

1955

1956

1957

1958 Apr. MERCURY-0; Infinite multiplication factor (HITACHI; FACOM-128)

Jun. One-dimensional critical calculation of BWR (NAIG; UNIVAC-120)

Aug. JUPITER-1; Criticality (HITACHI; HIPAC-1)

Two-group two-region code; Criticality (JAERI; IBM-650)

Sep. (Opening of IBM Computing center (IBM-650))

(Installation of IBM-650 (JAERI))

(Installation of Bendix GID (MELCO))

Calculation of fuel cycle (CRIEPI; FACOM-128)

Calculation of control rod effect (MELCO; Bendix G15D)

Dec. SUNRISE-2B; Two-dimensional critical calculation of BWR (HITACHI; HIPAC-1)

G2-1

1959 Jun. Completion of PACIFIC-series; Monte Carlo calculation of gamma-ray scattering (KAJIMA, IMS; FACOM-128)

Feb. Design calculation of fast reactor by PROD-II (CRIEPI; IBM-650) IBM Library

Mar. Calculation of temperature coefficient (MAPI; Bendix G15D)

(Installation of IBM.704 (The Meteorological Agency))

Apr. Calculation of Xe-oscillation of British-type power reactor (JAPCO; FACOM-128)

May (Series of calculations on a semi-homogeneous reactor (JAERI: IBM-650)

Jun. (Opening of Bendix Computing Center (Bendix G15D))

(Opening of JEIDA Computing Center (NEAC-2203, HITAC-301 etc.) 


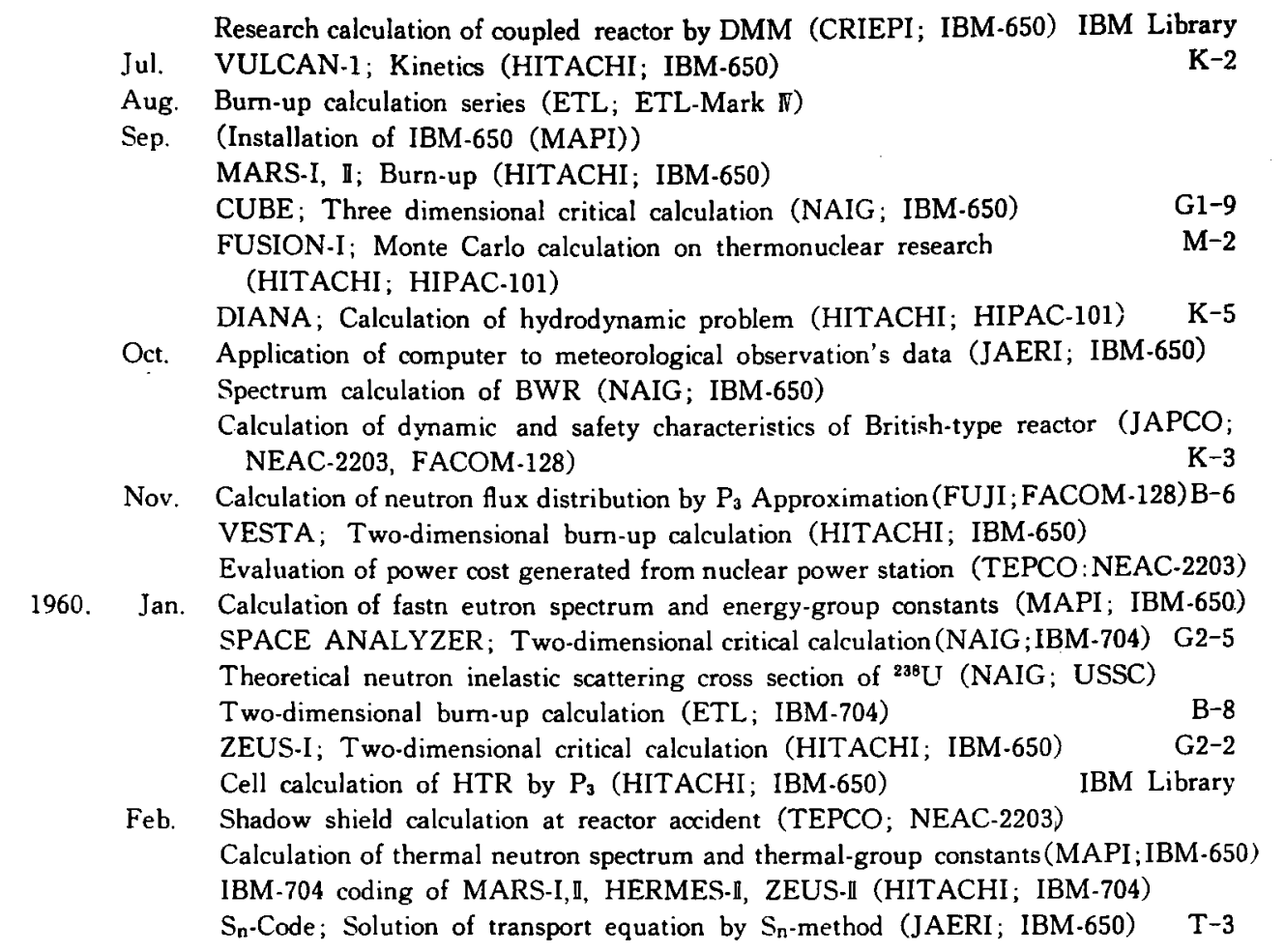

[Note: The right-most column shows the corresponding code number which appears in Part (II)]

\section{[Appendix B Brief Survey of Digital Computers in Japan}

The demand for the digital computer in this country has greatly increased with the progress of industry in the last few years. After the several years of fundamental research, domestic computers entered into the stage of commercial production. The Table B-I shows the characteristics of the domestic computers which are used for scientific purposes, including the nuclear reactor design calculation and the other related problems.

Since the capacity of these computers is not sufficient for the large scale problems which are often encountered in reactor calculation, several foreign machines have been imported, the list of which is shown in Table B-II. (The computers for scientific purposes only are described here.)
TableB-I List of non-domestic machines installed in Japan

\begin{tabular}{l|c|c}
\hline & In use & On order \\
\hline Bendix G15D & 3 & - \\
LGP 30 & 2 & - \\
DATATRON 205 & 1 & 2 \\
IBM 650 & 10 & 5 \\
704 & 1 & - \\
705 & - & 1 \\
7070 & - & 6 \\
I & - & 1 \\
UFC & 3 & 4 \\
USIVAC(UCT) & 3 & 9 \\
\hline
\end{tabular}




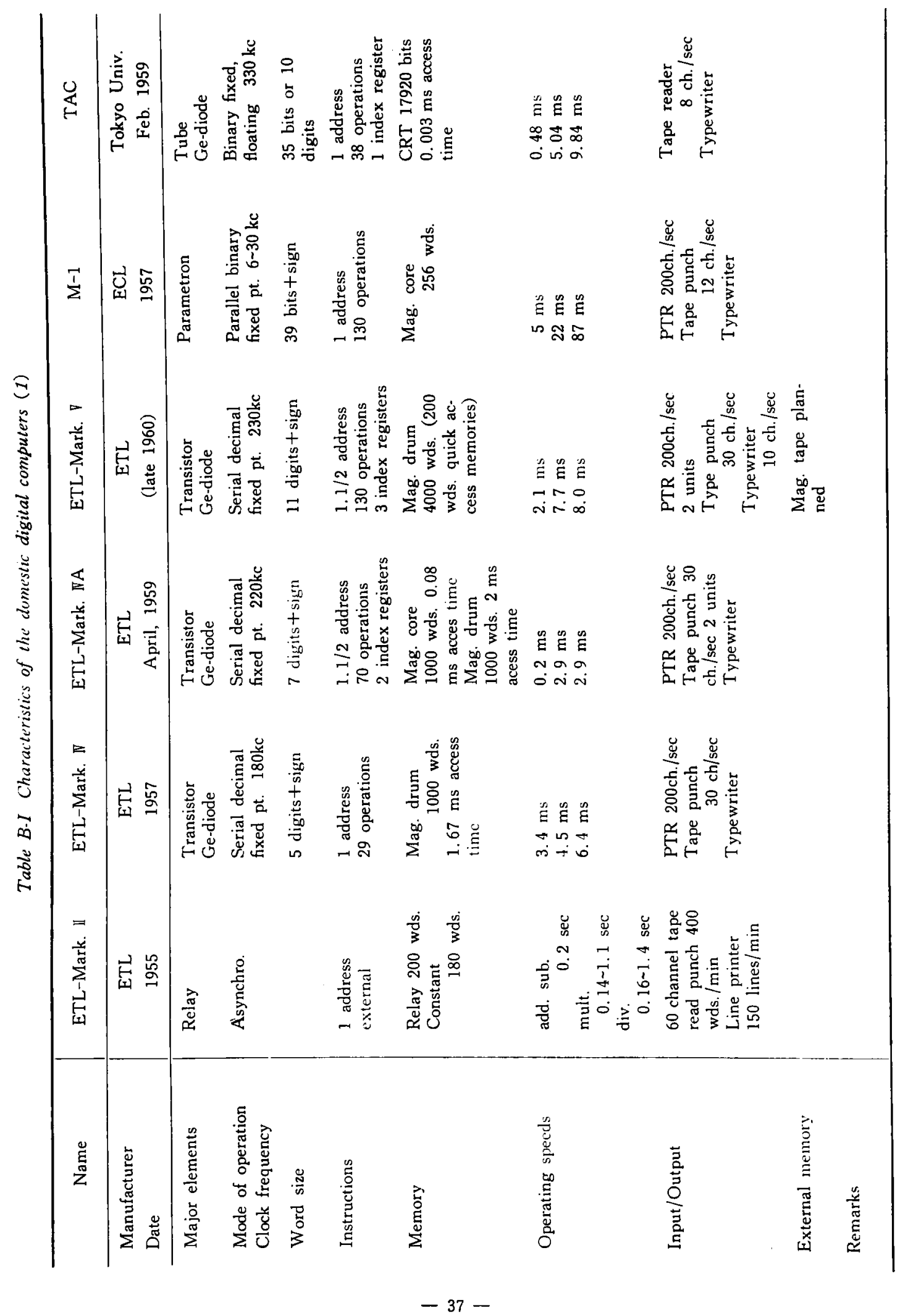




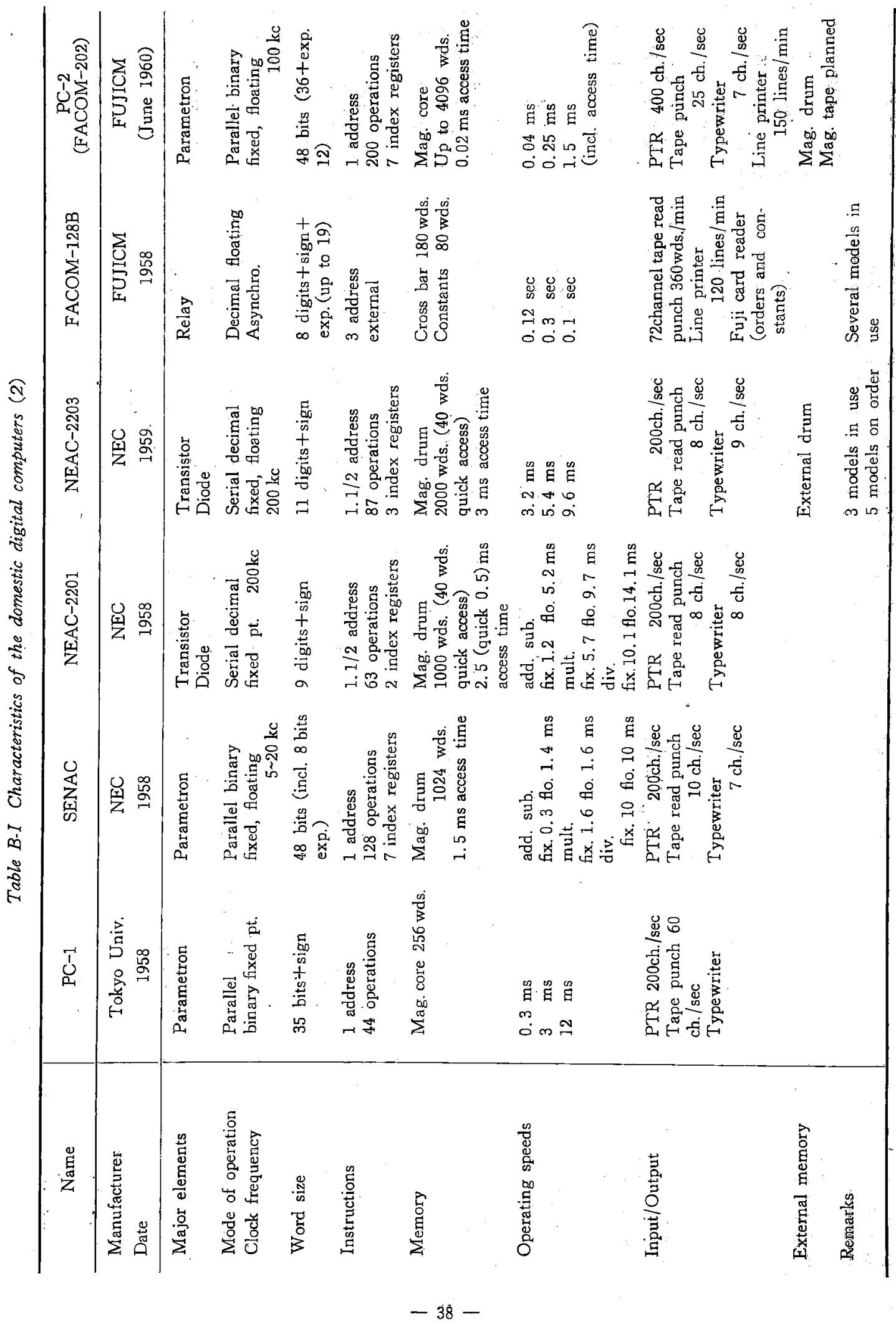




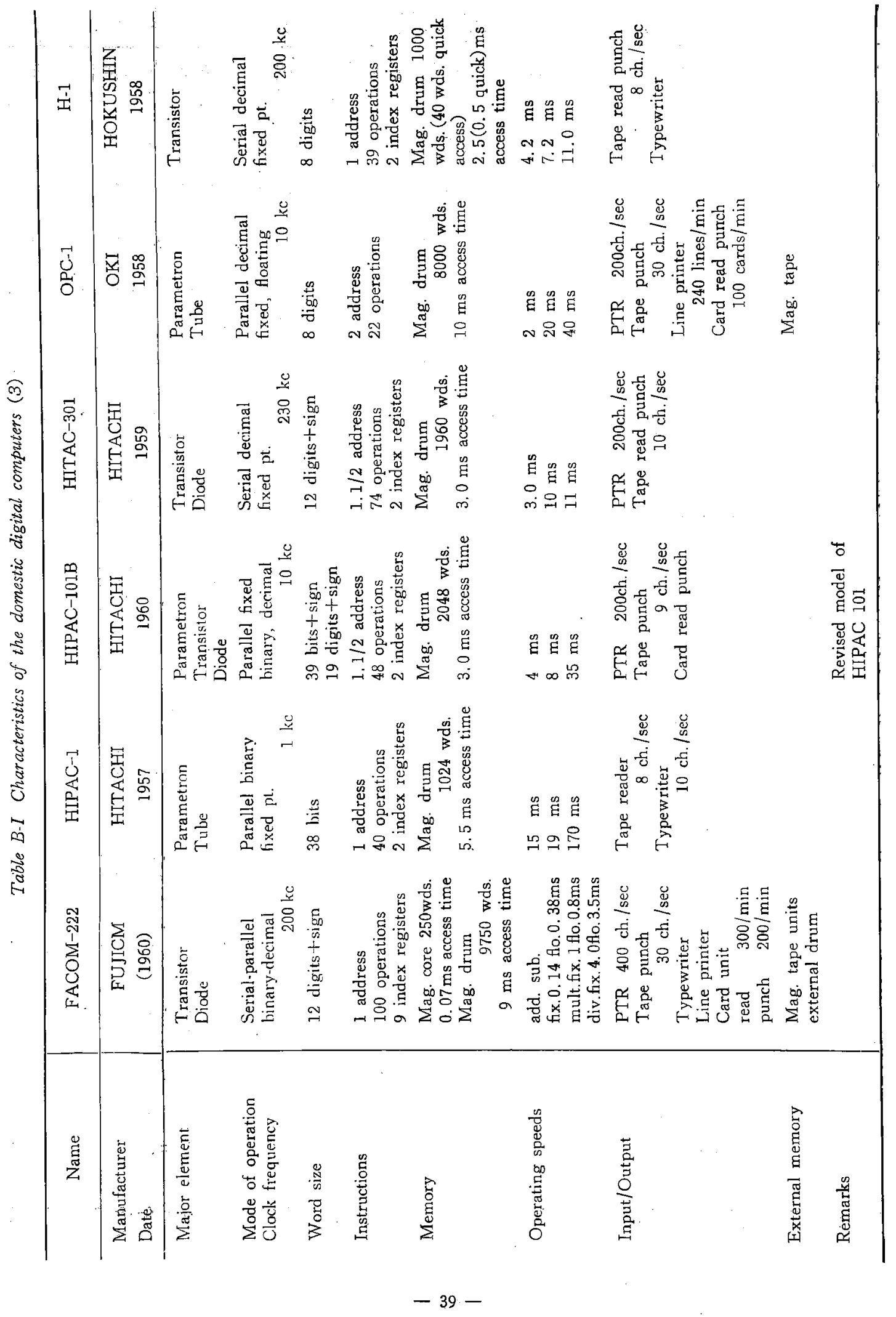


[Appendix C] Shieding Codes Group's Shielding Computer Program ${ }^{\dagger}$

\begin{tabular}{|c|c|c|c|c|c|}
\hline 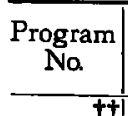 & Description & $\begin{array}{c}\text { No. of } \\
\text { dimen- } \\
\text { sions }\end{array}$ & Geometry & $\begin{array}{l}\text { No. of } \\
\text { energy- } \\
\text { groups }\end{array}$ & Calculation procedure \\
\hline SC 1011 & $\boldsymbol{\gamma}$ ray dose rates & 1 & $\begin{array}{l}\text { Slab, cylinder } \\
\text { and sphere }\end{array}$ & 8 & $\begin{array}{l}\text { Build-up method by analytical } \\
\text { treatment }\end{array}$ \\
\hline SC 1012 & $\boldsymbol{\gamma}$ ray dose rates & 3 & $\begin{array}{l}\text { Slab, cylinder } \\
\text { and sphere }\end{array}$ & 8 & $\begin{array}{l}\text { Build-up method by numerical } \\
\text { treatment }\end{array}$ \\
\hline SC 1021 & Neutron dose rates & 1 & $\begin{array}{l}\text { Slab, cylinder } \\
\text { and sphere }\end{array}$ & 3 & $\begin{array}{l}\text { Diffusion theory and fast neutron } \\
\text { removal theory }\end{array}$ \\
\hline SC 1022 & Neutron dose rates & 3 & $\begin{array}{l}\text { Slab, cylinder } \\
\text { and sphere }\end{array}$ & 3 & $\begin{array}{l}\text { Diffusion theory and fast neutron } \\
\text { removal theory by numerical } \\
\text { treatment }\end{array}$ \\
\hline SC 1031 & Capture $\gamma$ ray dose rates & 1 & $\begin{array}{l}\text { Slab, cylinder } \\
\text { and sphere }\end{array}$ & 8 & $\begin{array}{l}\text { Build-up method by numerical } \\
\text { treatment }\end{array}$ \\
\hline SC 1041 & $\begin{array}{l}\text { Reactor shield design } \\
\text { Shield weight analysis (unifi- } \\
\text { cation of 1011, 1021, 1031) }\end{array}$ & 3 & $\begin{array}{l}\text { Cylinder and } \\
\text { sphere }\end{array}$ & $\begin{array}{l}\mathrm{n}, 3 \\
\boldsymbol{\gamma}, 8\end{array}$ & $\begin{array}{l}\text { Same as } \mathrm{SC} 1031 \\
\text { (Parametric study for the mini- } \\
\text { mum weight) }\end{array}$ \\
\hline SC 1051 & Coolant activity & 1 & Cylinder & 5 & Build-up method \\
\hline SC 1061 & $\begin{array}{l}\text { Temperature and thermal } \\
\text { stress distribution in the shield }\end{array}$ & 1 & $\begin{array}{l}\text { Slab, cylinder } \\
\text { and sphere }\end{array}$ & 8 & $\begin{array}{l}\text { Temperature distribution due to } \\
\text { radiation }\end{array}$ \\
\hline SC 2011 & $\begin{array}{l}\text { Growth and decay character- } \\
\text { istics of fission products in } \\
\text { a fuel rod }\end{array}$ & & & & $\begin{array}{l}\text { Gross total }{ }^{235} \mathrm{U} \text { fission product } \\
\text { production as a function of ther- } \\
\text { mal neutron flux, irradiation } \\
\text { time and decay time }\end{array}$ \\
\hline SC 2012 & $\begin{array}{l}\text { Growth and decay character- } \\
\text { istics of fission products in } \\
\text { a fuel rod }\end{array}$ & & & & $\begin{array}{l}\text { Atomic concentrations as a func- } \\
\text { tion of thermal neutron flux, } \\
\text { irradiation time and decay time }\end{array}$ \\
\hline SC 2021 & $\begin{array}{l}\gamma \text { dose rates from fission } \\
\text { products in a containment }\end{array}$ & & & & $\begin{array}{l}\text { Dose rates of fission products } \\
\text { released in a containment }\end{array}$ \\
\hline SC 2031 & $\begin{array}{l}\text { Fission product release from } \\
\text { a containment }\end{array}$ & & & & $\begin{array}{l}\text { Factors influencing initiation, } \\
\text { propagation and rate of release } \\
\text { and dispersion of fission product } \\
\text { in the field }\end{array}$ \\
\hline $\mathrm{SC} 3011$ & $\begin{array}{l}\text { Monte Carlo neutron penetra- } \\
\text { tion }\end{array}$ & 1 & Multiple layer & & $\begin{array}{l}\text { Monte Carlo method } \\
\text { A uniform infinite beam of mono- } \\
\text { energetic neutron source }\end{array}$ \\
\hline SC 3021 & $\begin{array}{l}\text { Monte Carlo } \gamma \text { ray penetra- } \\
\text { tion }\end{array}$ & 1 & Multiple layer & & $\begin{array}{l}\text { Monte Carlo method } \\
\text { A uniform infinite beam of mono- } \\
\text { energetic } \gamma \text { source }\end{array}$ \\
\hline SC 3031 & Neutron scattering analysis & 3 & $\begin{array}{l}\text { Infinite homo- } \\
\text { geneous medium } \\
\text { (air, water) }\end{array}$ & & $\begin{array}{l}\text { Exponential attenuation } \\
\text { Distribution of scattered neutron } \\
\text { from an anisotropic point source }\end{array}$ \\
\hline SC 3041 & $\gamma$ ray scattering analysis & 3 & $\begin{array}{l}\text { Infinite homo- } \\
\text { geneous medium } \\
\text { (air, water) }\end{array}$ & & $\begin{array}{l}\text { Build-up method } \\
\text { Distribution of scattered } \gamma \text { ray } \\
\text { from an anisotropic monoenerge- } \\
\text { tic source }\end{array}$ \\
\hline SC 3051 & $\begin{array}{l}\gamma \text { ray penetration } \\
\text { Effect of irregularities in the } \\
\text { shield }\end{array}$ & 3 & $\begin{array}{l}\text { (a) Cylindrical } \\
\text { ducts } \\
\text { (b) Edge } \\
\text { (c) Small void }\end{array}$ & & $\begin{array}{l}\text { Monte Carlo method } \\
\text { Isotropic point source }\end{array}$ \\
\hline
\end{tabular}

